\title{
The Pastoral Power of Technology. Rethinking Alienation in Digital Culture
}

\author{
Katarina Giritli Nygren \& Katarina L Gidlund
}

Mid Sweden University, Sundsvall, Sweden, katarina.giritli-nygren@miun.se \& Mid Sweden University, Sundsvall, Sweden, Katarina.lindblad-gidlund@miun.se,

\begin{abstract}
The purpose of this paper is to rethink alienation in digital culture in the light of Foucault's "pastoral modalities of power". Pastoral power does not displace other conceptions of power, but provides another level of analysis when considering the forging of reasonable, responsible subjects willing and able to sustain alternative conceptions of power. We will draw particularly on the early writings of Marx and the recent poststructuralist developments concerning hegemony and superstructure in relation to technology. Technology as such is analysed in terms of the repercussions of the "design of the machine" in industrial technological contexts and the "design of digital culture" in digital technological contexts. Pastoral power not only directs our attention to the making of technologies, but also to the making of individuals capable of taking on responsibility for those technologies. This means that it is necessary to acknowledge the fact of the effective power of ideologies and their material realities.
\end{abstract}

Keywords: Digital culture, alienation, pastoral power, digital practices

\section{Introduction}

Applying a Marxist approach to twenty-first-century information society is demanding and rewarding in equal measure; demanding in terms of the complex lines of argument required to unpick largely hidden phenomena, yet rewarding for its fine-grained analytical tools that uncover the power structures in any historical materiality. We will draw particularly on the early writings of Marx (Marx, 1963, 1986) and recent poststructuralist developments concerning hegemony and superstructure, and argue that such an endeavour provides a better understanding of the practices of digital technology in our time. In a classical Marxian analysis of technology in twenty-first century information society, digital technology could almost be seen as reinforcing the principles of automation, exploitation, and rationalization, for example in the context of electronic performance monitoring systems that are enhancing many of the Tayloristic thoughts on productivity, division of labour, and surplus value (Aiello and Kolb 1995; Carayon 1993). However, we would like to draw attention to another side of technological development - digital practices operating in the private sphere - where we suggest a Marxian analysis is relevant if we are to understand the new ways of reproducing capitalism.

To this end, we revisit a Marxian understanding of alienation and technology in the light of Foucault's concept of pastoral power, so capturing the new ways of distributing power in the digital era. According to some of Foucault's followers, the modern era (like other eras) is marked by an all-encompassing social practice (see for example: Bocock and Thompson 1992). All the phenomena that are characteristic of this era are designed either to strengthen or to counteract this practice. Pastoral power as such does not displace other conceptions of power, but provides an additional level of analysis with which to examine the forging of subjects willing and able to sustain an all-encompassing social practice. To view alienation within digital cultures as a ramification of pastoral modalities of power makes it possible to discuss technology as operating in structures of thinking and action that often seem to be devoid of power relations in the digital era.

While there are contradictions between Marx's and Foucault's theories (see for example: Barrett 1991; McDonald 2002), we would argue that it is precisely because of these tensions that it is rewarding to analyse alienation in digital cultures. One of the most frequently mentioned contradictions between these two giants of theory concerns the possibility of causal explanations or the differences between why questions and how questions are posed. Marx's position is as follows:

The ideas of the ruling class are in every epoch the ruling ideas: i.e. the class, which is the ruling material force in society, is at the same time its ruling intellectual force. The class which has the means of material production at its disposal, consequently also controls the means of mental production, so that the ideas of those who lack the means of mental production are on the whole subject to it. The ruling ideas are nothing more than the ideal 
expression of the dominant material relationships, the dominant relationships grasped as ideas (Marx and Engels 1976, 59).

Marx and Engels's interest was primarily the material relationships that constitute ruling ideas. This line of reasoning implicitly creates an ontological explanation for the causal relationship between the ruling material forces, the ruling class, and the ruling ideas. Foucault, on the other hand, goes to lengths to avoid raising ontological questions, and instead focuses on epistemological questions, which here mean analysing how technology is intertwined with political prescriptions, power, and knowledge, and is embedded in socio-cultural practices. Socio-cultural practices are understood as the institutional and organizational circumstances in which the making of technology is situated. Since information society, like all kinds of societal transformations in history, is multidimensional, involving technological, economic, social, cultural, and political changes, it is necessary to analyse the strong image of information technology in relation to its twofold nature.

The implications of the differences in Marx's and Foucault's focus are here presented as a challenging way to move our understanding forward. We argue that this unconventional way of situating both thinkers in a theorization of digital culture provides an important avenue to reevaluating the contribution they might make. Using pastoral power as a lens, our discussion begins with an outline of the new modalities of power in digital culture, before moving on to a more analysis of alienation and reification in digital culture by revisiting Marx's early writings. We conclude with a discussion of objectification and subjectification. We argue that alienation and objectification are definitely still valid in digital culture, but have to be enriched by an understanding of the modalities of power in digital culture working in the processes of reification that produce objectified, subjectified, and subjectifying subjects.

\section{Modalities of Pastoral Power in Digital Culture}

Our starting-point is an analytical separation between the practices of industrial and digital technology, where industrial technology is closely related to the labour sphere and ideas of rationalization (see for example: Habermas 1970; Feenberg 2010). Digital technology, in addition to being related to the labour sphere as industrial technology, is also related to the private sphere and ideas of individualization. Such an additional understanding assists in the analysis of the distribution of power under the historical conditions surrounding digital culture. Furthermore, it provides an analytical approach to digital practices operating as ideologies or norms, while at the same time retaining the material historicity of locality and everyday life practices.

We will base our analysis of technology in general, and digital culture in particular, on an epistemological rapprochement between "practices" (see for example: Pacey 1999). In order to address digital practices in relation to alienation, we make an analytical distinction between the two different operations of technology practices, in part following Pacey (1999), who writes of the two faces of technology practice: an object-centred, mechanistic approach that dominates science, engineering, and technology, and which marginalizes everyday experiences and leads to a compartmentalized and alienated practice; and a more people-centred, convivial approach in which social meanings co-exist and interact with the personal responses and existential experiences of individuals. We use this dichotomy to understand technology's close relation to labour power distribution and rationalization, in line with many updated Marxian analyses of technology (Feenberg 2010), but we also view digital technology as being linked to individualization, where the subject is part of the power distribution process. This is not a bald statement of the fact that technology and humans are separable in modern society (since they are linked in many ways) - the task is rather to retune the analysis of power distribution.

Consequently, we understand digital technology as an analytical object "on the threshold of materiality" (Dunne 2005, 11), a view informed by the philosophical view of technology as being underdetermined. The undetermination of technological artefacts "leaves room for social choice between different designs", and these "have overlapping functions but better serve one or another social interest" (Feenberg 2010, 7). According to Feenberg this means that "context is not merely external to technology, but actually penetrates its rationality, carrying social requirements into the very workings of gears and levers, electric circuits and combustion chambers" (Feenberg 2010, 7). Digital technology has a material existence without defined tangible qualities, and as such could be adhered to in almost all possible future scenarios. The symbolic logic is translated into a form that is characteristic of the digital artefact, and it is both the acceptance of the symbolic logic and the performed practices themselves that become the object of analysis (see for example: Löwgren and Stolterman 2004). Technology is nothing but a mirroring of hegemonic social concepts (such as 
rationalization or individualization), but we need to create, update, and recreate tools to analyse its interaction with the distribution of power. Thus the opaqueness of digital technologies in twentyfirst-century information society calls for a deeper understanding of alienation and capitalism, analysing and criticizing the uniqueness of things digital.

Here, Marxist theories and concepts are exceptionally well placed, especially where the ambition is to unveil cultural production in relation to marketization. However, we think that such an analysis is not enough. The opaqueness of digital technologies calls for a more complex conceptualization that allows a deeper, more structural analysis of the ways in which power is displayed. It is necessary to analyse an understanding of power that goes beyond power as a relation between oppressors and oppressed, between worker and owner, or as an effect of the State, and it is to this end we advance a theoretical framework that draws on both Marx and Foucault. We argue that a Foucauldian analysis of power is needed if Marx's concepts of alienation and dialectical analysis are to have full rein in a critical analysis of the distribution of power in digital culture.

Foucault's concept of pastoral power was coined in his genealogical discussion of the historical development of the Christian Church and its gradual assimilation into modern State apparatuses. Its primary focus is the technologies and modalities of power as first developed in a Christian context (Foucault 1982, 2007). He shows that during the eighteenth century, pastoral power found a new way of distributing this kind of individualizing power. The modern State developed as a sophisticated structure into which individuals could be integrated, given one condition: that their individuality would be shaped in a new form and submitted to a set of very specific patterns. The State, according to Foucault, should be seen as modern matrix of individualization-a new form of pastoral power. Foucault argues that pastoral power is reproduced by human beings themselves; the human being turns himself into a subject. At first the subjects were "the body of the religious soul", then "citizens", then "workers", and now they are "cultural beings" (see Touraine 2007). In the transformation from Christian to State modalities of pastoral power, Foucault characterized pastoral power as follows (Foucault 1982, 784):

(i) It is a form of power whose ultimate aim is to assure individual salvation in this world.

(ii) It is not merely a form of power that commands, it must also be prepared to sacrifice itself for the life and salvation of the flock.

(iii) It is a form of power that does not look after just the whole community, but each individual in particular, during his/her entire life.

(iv) It is a form of power that cannot be exercised without knowing the inside of people's minds, without exploring their souls, without making them reveal their innermost secrets. It implies knowledge of the conscience and an ability to direct it. We argue that pastoral power has once again found a new way of distributing individualizing, and subjectifying power - this is what we call the pastoral power of technology.

We are addressing the process of subjectification, not as "the subject", but as "the storying of the self" (see for example: Rose 1996; Deleuze 1990; Derrida 1978). Subjectification is seen as arising from a regime, and this regime is tied to assemblages of power - in the present case, the pastoral power of technology, making the logic that of performing our multiple selves as commodities. The proposition is that this is an expression of our own will. So we the authors, for example, are performing ourselves as "elitist intellectuals" resistant to the possibilities of the market to attach lifestyle commodities to our performances. These performances are what is sayable, audible, operable, and performable, while other phenomena are not. Digital technologies effectively mask the origin of the relevant discursive practices, which are located in particular sites and procedures even though pastoral power disguises them effectively as logics of individualization and selfperformance. The practices are pre-personal, structured into relations that grant power to some and limit the power of others. As such, the self is understood not as a mental mechanism, but as conversations, grammar, and rules. We must perform this way (see for example: Rose 1996).

It is also this dialogic character of self-narrative that demands a closer analysis when it comes to digital technology. Self-narratives are culturally provided stories about selves that serve as the resources with which individuals can interact with one another and with themselves (Rose 1996). By a combination of training and technological possibilities, we are becoming more and more skilled in performing ourselves (our multiple self-narratives). As a result, pastoral practice is increasingly being honed. The dialogic character of our self-narratives is also strengthened by digital technologies, since the responses (the interactional nature of subjectification) are more easily amplified (for example, by "liking" on Facebook, leaving blog comments, etc.). It is therefore also important to turn to the techniques and apparatuses of the regime. The pastoral power of digital technology adds to this by convincing individuals that the choices they make in the staging of 
their selves is their own, and that they are making these choices as expressions of their individuality. We are becoming willing and efficient self-governing subjects. By addressing things digital as a means of persuasion, exposure, amplification, and transmission, and as subjectification processes and performances, these circumstances are made more visible. The opaqueness of digital technology is exposed and made an object of study. The specific historical conditions of digital technology allow the process of individualization to colonize the lifeworld in a very effective manner:

(i) Digital technologies amplify the exposure of our self-narratives (our performances).

(ii) Digital technologies speed up the transmission of self-narratives (our performances).

(iii) Digital technologies amplify the number of responses, so strengthening interactional subjectification.

(iv) Digital technologies speed up the response time for interactional subjectification.

(v) Digital technologies enable multiple self-narratives in a more efficient manner.

(vi) Digital technologies (software such as photoshop, hardware such as digital cameras or smartphones) facilitate the creation of multiple self-narratives.

(vii) Digital technologies enable congruent self-narratives.

Drawing on the arguments Foucault presents, we propose that digital technology can be viewed as a modern matrix of individualization or as a specific form of pastoral power. Foucault writes of the State modalities of power, yet consider the following quotation when the term "the State" is replaced by "digital technology":

I don't think we should consider [digital technology] as an entity which was developed above individuals, ignoring what they are and even their very existence, but on the contrary as a very sophisticated structure, in which individuals can be integrated, under one condition: that this individuality would be shaped in a new form, and submitted to a set of very specific patterns (Foucault 1982, 783).

Digital technology allows the subject to individualize, to stage the self, and, as such, the technological (digital) potential seduces the subject with the idea that with digital technology we can construct and display individuality. In the same way as automated technologies are embedded with rationalization (the social concept of a rationality that co-constructs society), digital technologies are embedded with individualization (individualization as an equally social concept co-constructing society). Pastoral modalities of power involve the entire history of processes of human individualization; saying that one does not want to express individuality with the help of digital technology sounds as awkward in our digital society as refusing to act in a rational way sounded in industrial society. Because this individualization is left unquestioned, it appears all members of society find it of interest-universal, neutral, natural, and inevitable. Yet where Foucault talks about "the mad and the sane, the sick and the healthy" (Foucault 1982, 778), our argument turns on precensorship versus the censured, what is staged versus what is behind the scenes, the performed versus the unscripted, and the displayed versus "the dislocated" and "the localized".

\section{Marx Revisited}

In modern societies, knowledge is conjoined with power and together they produce individual subjectivity and the social order. Marx's works offers excellent tools to analyse objectifying practices, but when it comes to analysing subjectifying practices, they have some shortcomings. There are also clear connections between Marx's analysis of capitalism and Foucault's conception of disciplinary power. For example, Foucault clearly states that the rise of disciplinary power was a central feature of modern society that went hand in hand with the development of the capitalist mode of production, which needed a labour force both subjected to and better utilized by its system (see Marsden, 1999). Foucault also contrasts Marx's economics of untruth with the politics of truth - the first focuses on the relation between economic, material praxis, and ideology, while the second focuses on the relationship between knowledge, discourse, truth, and power. To capture the opaqueness of digital technology, we think it is necessary to keep both theories in mind, especially as Foucault's concept of pastoral power speaks to the subjectifying practices of digital technology, not only its objectifying practices. Foucault's notion of pastoral power is based on the metaphor of the relationship between the shepherd and his flock (Foucault 2007, 125-130), where the shepherd gathers and defines his flock and each member of the flock is saved by the shepherd's individualized goodness - the shepherd, in other words, takes control of the individuals through individualizing techniques. Pastoral modalities of power are based on people's freedom of choice, but have a controlling function that makes them choose what is deemed necessary. 
Humans are as much controlled when they are created as objects as when they are created as subjects, at least as long as their subjectivities confirm hegemonic practices (Foucault 1988).

Digital technologies can be understood as an institution producing and sustaining new forms of transnational material relationships that make the ruling classes even more invisible, as well as an institution that produces new subjectivities and new forms of governing that involve the activating rhetoric of neo-liberalism. Foucault (2007) describes the pastoral modalities of power as a power linked to the production of truth and a unique combination of individualization and totalization. As such, the conceptual advantages of situating pastoral modalities of power within the understanding of alienation in digital culture offers a clearer view of how the practices of power become processes of subjectification within digital cultures: it offers a dialectical understanding of reification and individualization.

Certainly, digital technologies in twenty-first-century information society are of an opaqueness that calls for a greater understanding of alienation and capitalism, and the question of their uniqueness should be analysed. Marxist theories and concepts are exceptionally well placed to unveil cultural production in relation to marketization, but equally, such an analysis is not enough, for the opaqueness of digital technologies calls for a more complex conceptualization, which allows a more detailed, structural analysis of the ways in which power is displayed. It is necessary to analyse an understanding of power that goes beyond that of power as a relationship between oppressors and the oppressed. Moreover, we see the opaqueness of digital technology as something different and more complex than industrial technology, where ideal expressions of dominant material relationships, not to mention the material distribution of hegemonic, neo-liberal ideas, have to be taken into account. While Marx focuses on material conditions rather than ideas, Foucault focuses on ideas as material conditions (see for example: Foucault 1984).

There is much to revitalize thinking about twenty-first-century information society in the works of Marx. The concepts of alienation and reification offer good starting-points in better understanding the "digital" element in digital cultures. As is well known, Marx articulated his theory of alienation most clearly in the Economic and Philosophic Manuscripts (1988) and The German Ideology (1976). His critique extends to both Feuerbach and Hegel, while discussing and acknowledging other forms of alienation such as political alienation and religious alienation. For Marx, the alienation of labour is the most basic form of alienation (Marx and Engels 1976): built on a particular form of wage labour, is for him a systematic result of capitalism (Marx and Engels 1976, 1988).

Alienated individuals have to be alienated from something, as a result of certain objectifying and dualistic practices that manifest themselves in the historical framework. Alienation is then a consequence of human totality and human self-consciousness standing in opposition to each other. As such, religious alienation is connected with the dualistic construction of body and soul, or the empirical life on earth and the spiritual life in heaven, whereas political alienation is connected with the (bourgeois) dualistic creation of the individual as abstract citizen and private human being (Marx 1963). In his analysis of the alienation of labour, Marx stresses two points:

(i) In the process of work, and especially work under the conditions of capitalism, man is estranged from his own creative powers, and,

(ii) The objects of his own work become alien beings, and eventually rule over him; they become powers independent of the producer (Marx 1963).

This form of alienation means, for Marx, that individuals do not experience themselves as the acting agents, but that the world (Nature, others, and he himself) remains alien to them. They become reified and appear as objects, even though they may be objects of their own creation. In a capitalist society, workers can never become autonomous, self-realized human beings in any significant sense, except in the way the ruling class wants the workers to be realized. They can only express this fundamentally social aspect of individuality through a production system that is not publicly social, but privately owned; a system for which each individual functions as an instrument, not as a social being (Marx 1963).

When differentiating industrial from digital technology, it becomes apparent that Marx's theory of alienation is very much based upon his observation of emerging industrial production (for a similar discussion, see Feenberg 2010). Marx developed his theories during the era of modern industry, when workers were assembled in large factories or offices to work under the close supervision of a hierarchy of managers who were the self-appointed brains of the production process. Workers could be seen as extensions of machines rather than machines being the extensions of workers. This type of analysis of alienation is still valid in the twenty-first-century information society. Digital technologies also enhance many of the industrial phenomena of productivity, division of labour, and surplus value (Aiello and Kolb 1995; Carayon 1993), which shows that information society is not 
only, if at all, a post-industrial society. But, if we return to the question of digital technology and its opaqueness, we take our lead from Marx in suggesting that it is necessary to talk of a new form of alienation that has emerged with the Internet and information society - "digital alienation", which with its dislocated virtual life constructs a dualistic relation between dislocated and located forms of being (online/offline identities). The life situation (whether digital or virtual) is still located; the image of liberation, disengagement, and loss of stability is (to paraphrase Marx) part of this epoch's "ruling ideas", meaning the ideas of the ruling class. It is a widespread contemporary belief that increased economic globalization, together with online communication, will reduce the importance of geographical sites as a base for people's identity (see, for example, theorists such as Giddens 1990; Virilio 1993; Negroponte 1995). The construction of "placelessness" and a possible dissolution of space and time give rise to a new form of alienation - digital alienation - that reproduces and hides class conflicts in contemporary global societies.

According to Marx, the alienation of labour occurs when the worker is alienated from the product of his work and therefore becomes alienated from work itself. His argument is that it is essential to human beings to express ourselves creatively, but that we lose contact with ourselves if this is not the case in our own working conditions. In industrialized society, working conditions deny us control of our work and the world we live in. The line of argument for digital alienation is similar, but based on the process of individualization. We position digital alienation alongside the alienation of labour, in much the same way as religious and political alienation are positioned alongside the alienation of labour: as an objectifying and dualistic practice. Human totality is alienated from selfconsciousness, and the digital "self" becomes a commodity. The subject might resist, but is constantly undermined by the relation to the "screen". We are "seduced" by the world of consumption into performing our self on the digital stage. Here the individual is merely a screen onto which the desires, needs, and imaginary worlds manufactured by the new communications industries are projected. Those who no longer find the guarantee of their identity within themselves are ruled, indistinctly, by what escapes their consciousness (see Touraine 2007, 101).

For example, individuals perform themselves on the stage of digital culture, and their control of the performance is lost because of the conditions of the digital performance (Facebook, Twitter, blogs, etc.). We are no longer in control of the "self" we perform. We censor our thoughts and our images in relation to the expected (the life-styling logic) and the product/the self becomes alienated. We lose control of our digital selves and the world we live in, and it is hard to feel committed to the self since the analogue or localized life is separated from the digital. Neo-liberal subjects become dependent on the labour market, and ultimately on education, consumption, welfare state regulations and support, consumer supplies, and on possibilities and fashions in medical, psychological, and pedagogical counselling and care. This all points to the institutiondependent control structure of capitalist hegemony. With the advent of digital technology and neoliberalism, the norms and hierarchies governing the processes of capitalistic hegemony tend to be hidden, and the processes themselves become mystified as nothing but the outcome of free individual choice (see Mosco 2004).

According to Marx, it is not until real individuals, in their individual circumstances, become one with their empirical lives that they can realize themselves as authentic social beings (Marx and Engels 1963). This line of thought is not unproblematic, since it is based on certain fundamental assumptions concerning the conditions for the self-realization of a possible, total, and authentic self, which is clearly related to Hegel and the Bildung tradition (for a more detailed discussion, see for example: Levine 2012). This is why the understanding of alienation in digital culture would be better redirected towards the analysis of processes of reification embedded within the pastoral modalities of the power of technology, where reification specifies the dialectic relationship between social existence and social consciousness. What we want to avoid is the social structural dimension disappearing, reducing alienation and reification to the level of a psychological characteristic of an abstract individual. To focus on the processes of reification means that we need to understand relations of power, recognizing that it is more important to analyse the processes that lead to alienation rather than the alienated condition as such. The concept of reification is used by Marx to describe a form of social consciousness, in which human relations come to be identified with the physical properties of things, thereby acquiring an appearance of naturalness and inevitability. To focus on processes of reification then means analysing how human relations operate and what they signify, which is, we argue, a theoretical standpoint very similar to Foucault's theory.

The multidimensionality of both the concepts of alienation and reification, and specifically the insights they provide into the inner structure of capitalist relations, show how capitalist social relations are materialized in the shape of the Internet. As such, they are built into information and 
communication technologies, and, because of the pervasiveness of commodity relations, they provide a fertile ground for reified forms of social consciousness. Based on the growth of digital technologies, new forms of reification have emerged.

Bringing the pastoral power of technology to an analysis of underlying social relations that produce alienation and reification provides a model for a more general analysis of the nature of technological and ideological mystification in contemporary neo-liberal and capitalist societies. This means that alongside the fetishism of commodities we also have the fetishism of technology. Where once the worker employed the instruments of production, now the instruments of production employ the worker.

\section{A Multifaceted Analysis of the Distribution of Power}

At the start of this paper, we proposed rethinking alienation and power in digital cultures. By proposing a dialectical analysis of digital technologies in relation to superstructure and base, hegemony and everyday practices, we have reappraised the understanding of alienation in twentyfirst-century digital culture by viewing it in terms of the pastoral power of technology in order to analyse the opaqueness of digital practices. Pastoral power not only directs our focus to the relation between power and technological practices, but also to the making of individuals who willingly take on the responsibilities of power. This shows that it is necessary to focus on the notion of the effective power of ideologies and their material reality.

In talking about alienation in digital culture, we suggest it is crucial to note the specific type of alienation that arises in the era of digital technologies. It is of the outmost importance to analyse alienation in digital culture as a result of certain objectifying and dualistic practices when using Marx's theory. For the fundamental alienation of labour, Marx emphasizes that we do not experience ourselves as the acting agents in our grasp of the world; with digital technology, we do experience ourselves as acting agents. However, it does not matter how virtual the subject might be, there is always a positioned and localized body of experience and everyday life attached to it, from which the virtual subject is alienated. In this way, digital technologies are able to cause an illusionary feeling of subjectification and agency without having any empirical consequences - it is possible to voice opinions and thoughts without anyone listening. In similar vein, Fuchs (2008, $2009,2010)$ states that social networking platforms are ideological expressions of individual creativity that create the illusion that individual expression counts in capitalism because they can be published online. Furthermore, he discusses the complex connections between the objectifying and subjectifying practices of digital technologies that are based on instrumental reason, but driven by active play labour (ibid.). This form of alienation results in what Fuchs (2010) calls a "total commodification of human creativity" (see also Smythe's original analysis of audience commodification (2006)). This is very much in line with a Foucauldian power/knowledge dystopia, in which even moral and practical knowledge are transformed into cognitive and technical systems that normalize and regulate what was previously private (see Lash 2007). And here the reason to adduce Foucault's theory becomes obvious since it permits a more flexible exploration of digital cultural and subjective phenomena. A Marxian approach to analysing the distribution of power is still needed in the twenty-first century. It provides analytical tools that not only expose alienation and reification in terms of material conditions of labour (extreme Taylorism), but also reveal alienation and reification in terms of material and objectifying practices in digital culture. Furthermore, an analysis of the subject as a target for commodification and dislocation allows us to see how reification is performed and operates today. For a better understanding of reification in digital culture, we have supplemented Marx's concept of reification with Foucault's concept of pastoral power to reveal the subjectifying practices. The analysis shows that the subject is an object of different modalities of pastoral power, for example in the ideology that holds that there are unique opportunities to express individuality in digital practices. Digital practices enable the subject to perform individualization, to stage the self, and, as such, they seduce the subject with the thought that with digital technology it is possible to construct and display individuality.

This theoretical construct draws attention to another level of analysis: the multifaceted analysis of the distribution of power in terms of the sublime equilibrium of objectified, subjectified, and/or subjectifying subjects. Neither Marx's nor Foucault's analysis is completely dystopian, as both leave room for resistance and action. By adding a careful analysis of the distribution of power, subjectification, and subjectifying processes (see, for example, Touraine 2007), another balance is struck. When Touraine address the image of a self and the subject, he draws a clear distinction between the notion of a subjectified subject and the subject in Foucault's pastoral power, and adds the idea of the subjectifying subject who has the ability to resist and to reflect. In the pairing of subject and subjectifyer, creator and created, liberator and imprisoned, the subjectification- 
reflecting subject resists the subjectifying practices. By focusing on processes of reification, the combined framework of Marx and Foucault successfully addresses both the procedures of objectification and subjectification in digital practices: objectification as an extension of competitive rationalization and domination (in other words, an extension of industrialization with the help of digital practices) and subjectification as commodification of the subject (or the marketization of the self), where, for example, the naturalization of certain capitalist values that turn the consumer into the ideal citizen takes place across national borders. Moreover, digital technologies have also been employed as modes of surveillance. As a consequence, control and power in digital culture manifest an increasing tendency towards the total surveillance and administration of society conducted through globally gathered and sorted digital information. Citizens, thanks to digital technologies, are becoming increasingly transparent to private and public monitoring agencies. The leading companies such as Apple, Google, Amazon, and Facebook have integrated data about our locations, preferences, or life events that are already put to use in various economic, political, and social contexts (see Andrejevic 2009). This paper has shown how the relationship between the distribution of power in digital practices in terms of objectification as a prolonged modernity, where everything is objectified and shaped according to commercial, rational and instrumental thinking, and subjectification as the expression of ultra-modernity, where instrumentality is supported by the illusory and ideological image of individual self-choice, could simultaneously be analysed as processes of reification within the digital pastoral modalities of power.

Reification then refers to two contemporary regulatory digital practices:

(i) processes of domination by others and/or subordination to an alien system of power, and

(ii) processes of being invented as a subject of a certain type.

Digital technologies have made it possible to govern in an advanced, liberal manner, providing a surplus of indirect mechanisms that translate the goals of political, social, and economic authorities into individual choices and commitments.

The task of global chains of production within digital societies is as much about producing subjects as it is about providing jobs and generating profit. However, it is important to also note that such a multifaceted analysis also touches on the transcendent balance between dystopia and utopia. We are not arguing for one or the other, but for revealing the full extent of the distribution of power and the potential for practices of resistance. Online activities, after all, also hold the promise of new forms of citizenship, communities, and political practice (see, for example, Bernal, 2006)

\section{References}

Aiello, John R. and Kathryn J. Kolb. 1995. Electronic Performance Monitoring and Social Context: Impact on Productivity and Stress. Journal of Applied Psychology 80 (3): 339-353.

Andrejevic, Mark 2009. ISpy: Surveillience and Power in the Interactive Era. Kansas: University Press of Kansas.

Barrett, Michele 1991. The Politics of Truth: From Marx to Foucault. Cambridge: Polity Press.

Bernal, Victoria. 2006. Diaspora, Cyberspace and Political Imagination: The Eritrean Diaspora Online. Global Networks 6 (2): 161-179.

Bocock, Robert and Kenneth Thompson, eds. 1992. The Social and Cultural Forms of Modernity. Oxford: Polity Press.

Carayon, Pascale 1993. Effect of Electronic Performance Monitoring on Job Design and Worker Stress: Review of the Literature and Conceptual Model. Human Factors: Journal of the Human Factors and Ergonomics Society,35 (3): 385 395.

Deleuze, Gilles 1990. Entretien sur Mille Plateaux., translated by S.-O. Wallenstein. Paris: Minuit (originally published in Libération, 23 October 1989).

Derrida, Jacques. 1978. The Dangerous Supplement. Of Grammatology. Translated by Gayatri Spivak, 141-164. Baltimore, MD: John Hopkins University Press.

Dunne, Anthony. 2005. Hertzian Tales, Electronic Products, Aesthetic Experience, and Critical Design. Cambridge, Mass.: MIT Press.

Feenberg, Andrew. 2010. Marxism and the Critique of Social Rationality: From Surplus Value to the Politics of Technology. Cambridge Journal of Economics 34 (1): 37-49.

Foucault, Michel. 1982. The Subject and Power. Critical Inquiry 8 (4): 777-795.

Foucault, Michel. 1988. Politics, Philosophy, Culture. Interviews and Other writings 1977-1984. New York: Routledge.

Foucault, Michel. 2007. Security, Territory, Population: Lectures at the Collège de France, 1977-1978. New York \& Basingstoke: Palgrave Macmillan.

Fuchs, Christian 2008. Internet and Society: Social Theory in the Information Age. New York: Routledge.

Fuchs, Christian. 2009. Information and Communication Technologies and Society: A Contribution to the Critique of the Political Economy of the Internet. European Journal of Communication 24 (1): 69-87.

Fuchs, Christian. 2010. Class, Knowledge and New Media. Media Culture and Society 32 (1): 141-150.

Giddens, Anthony. 1990. The Consequences of Modernity. Oxford: Polity Press.

Graham, Stephen. 1998. The End of Geography or the Explosion of Place? Conceptualizing Space, Place and Information Technology. Progress in Human Geography 22 (2): 165-185.

Habermas, Jürgen. 1970. Technology and Science as 'Ideology'. In Toward a Rational Society: Student Protest, Science, and Politics, translated by Jeremy Shapiro, 81-127. Boston: Beacon.

Hunt, Alan J. 2004. Getting Marx and Foucault into Bed Together! Journal of Law and Society 31 (4): 592-609. 
Lash, Scott. 2007. Power after Hegemony: Cultural Studies in Mutation? Theory, Culture \& Society 24 (55): 55-87.

Levine, Norman 2012. Marx's Discourse with Hegel. Basingstoke: Palgrave Macmillan.

Löwgren, Jonas and Erik Stolterman. 2004. Design av informationsteknik, materialet utan egenskaper. Lund:

Studentlitteratur.

Marsden, Richard 1999. The nature of capital: Marx after Foucault. London: Routledge.

Marx, arl. 1963. Early Writings, translated and edited by T. Bottomore. London: C. A. Watts.

Marx, Karl 1986. Karl Marx: The Essential Writings, edited by F. L. Bender. Boulder: Westview.

Marx, Karl and Friedrich Engels. 1976. The German ideology. Marx and Engels Collected Works, V. 19-539. Moscow: Progress.

Marx, Karl and Friedrich Engels. 1988. Economic and Philosophic Manuscripts of 1844: and the Communist Manifesto. London: Prometheus Books.

McDonald, Bradley J. 2002. Marx, Foucault, Genealogy. Polity 34 (3): 259-284.

Mitchell, William J. T. 2002. Showing Seeing: A Critique of Visual Culture. Journal of Visual Culture 1 (165): 164-181.

Mosco, Vincent. 2004. The Digital Sublime: Myth, Power and Cyberspace. Cambridge: MIT Press.

Negroponte, Nicholas. 1995. Being Digital. London: Hodder \& Stoughton.

Pacey, Arnold 2001. Meaning in Technology. Cambridge: MIT Press.

Rose, N. 1996. Inventing Our Selves: Psychology, Power and Personhood. Cambridge: CUP.

Thorpe, Ann. 2007. The Designer's Atlas to Sustainability. Washington, DC: Island Press.

Smythe, Dallas W. 2006. On the Audience Commodity and its Work. In Media and Cultural Studies: Keyworks, edited by Meenakshi G. Durham and Douglas M. Kellner, 230-256. Malden: Blackwell.

Touraine, Alain. 2007. A New Paradigm for Understanding Today's World. Cambridge: Polity Press.

Virilio, Paul 1993. The Third Interval: A Critical Transition. In Rethinking Technologies, edited by Verena Andermatt-Conley, 3-10. London: University of Minnesota Press.

\section{About the Authors}

Katarina Giritli Nygren

Katarina Giritli Nygren is senior lecturer in Sociology at Mid Sweden University. Her research focus is twofold. The one concerns rethinking technology in digital cultures in order not only to enlarge our understanding of the nature of technology, but also to provide tools with which to analyse how it strengthens or counteracts established practices. The other concerns place as a site where processes of normalization are located in terms of inclusion and exclusion in relation to ethnicity, gender, and class.

Katarina L Gidlund

Katarina L Gidlund is associate professor of Informatics at Mid Sweden University. Her main research interest is critical studies of digital technology and societal change. This involves issues such as critical and reflexive design, defamiliarization, the discursive level of design, and the interplay between rhetoric and practice (hegemonies and their material practices, power structures, the visualization of dominant stories, and embedded internationalities). She is cocoordinator of the Swedish eGovernment Research Network, programme committee member of the International EGOV conference and the Scandinavian Information Systems Conference, and editorial board member of the International Journal of Public Information Systems. 